\title{
Social Manufacturing: from the theory to the practice
}

\author{
Renata Mariani Zanella1 (1), Enzo Morosini Frazzon ${ }^{1}$ (D), Iracyanne Retto Uhlmann ${ }^{1}$ (1) \\ ${ }^{1}$ Department of Industrial Engineering, Federal University of Santa Catarina, Florianópolis, SC, Brazil.
}

How to cite: Zanella, R.M., Frazzon, E.M. and UhImann, I.R. (2022), "Social Manufacturing: from the theory to the practice", Brazilian Journal of Operations \& Production Management, Vol. 19, No. 3,

e20221241. https://doi.org/10.14488/BJOPM.2021.047

\begin{abstract}
Goal: This scientific research article focuses on understanding the new manufacturing paradigm of Industry 4.0 called social manufacturing. The study aims to consolidate the concept of social manufacturing by characterizing and evaluating its theoretical potential, identifying its main practical trends, and correlating its state-of-the-art with its state-of-the-practice.
\end{abstract}

Design / Methodology / Approach: The first step was the consolidation of the concept of social manufacturing through bibliographic analysis. Then, real-world cases were identified and classified under the optics of social manufacturing to define the current practice. Lastly, confronting the concept of social manufacturing with existing methods depicted a clear panorama, including academic and practical opportunities.

Results: The results show a trend towards social manufacturing. New challenges, including the COVID-19 pandemic, are pushing forward social collaboration initiatives related to manufacturing. The most advanced conceptualized stage occurs theoretically, as mass individualization is still not a reality. New scenarios of limited resources and challenging environments such as the COVID-19 pandemic will impose the broader dissemination and application of mass customization concepts, practices, and tools.

Limitation of the investigation: This research only considered articles published in English. Practices were analyzed using third-party content available.

Practical implications: New scenarios of limited resources and challenging environments such as the COVID-19 pandemic impose the broader dissemination and application of mass customization concepts, practices, and tools.

Originality / Value: The term social manufacturing in the literature has yet to be consolidated. In addition, no comparison between theory and practice was available.

Keywords: Social Selling; Mass Individualization; Mass Customization; Distributed Production; Prosumers; Crowdsourcing; Sharing Economy.

\section{INTRODUCTION}

Since the first industrial revolution, consumers have taken on an indirect role in designing and producing material goods. However, with novel digital technologies and communication, consumers have gradually increased their participation in co-creation activities. Nowadays, involvement in the innovation process has passed beyond being restricted to professionals (Rayna and Striukova, 2016). Therefore, the customer becomes a prosumer (pro = producer and sumer = consumer), having a double role of consumer and producer. Moreover, prosumers have focused on distributive forms of problem solving for the systematic

Financial support: None.

Conflict of interest: The authors have no conflict of interest to declare.

Corresponding author: remzanella@gmail.com

Received: 20 May 2021

Accepted: 26 Sep 2021.

Editor: Julio Vieira Neto. 
processing of information and resources, such as outsourcing and crowdsourcing. These practices allow for better services and products, adding more value to consumers (Jiang and Leng, 2017).

Lu (2017) affirms that information technology-enabled mass customization of manufactured products is one of the goals of Industry 4.0, providing new types of services and business models such as interaction in the value chain, among other things. The global market is rapidly changing, and users' necessity is becoming more individualized. Additionally, the competition between manufacturing companies is growing, creating the need for adaptation within companies, accomplished by organizational transformation (Xue et al., 2019). To cope with these challenges, companies may evolve from a business model in which they possess products and services to one in which they offer access to products and services, known as sharing economy.

This new model has the potential to influence other industries (Mohajeri, 2016). Wellknown examples of this business model transformation in the service industry are Uber and Airbnb (Hamalainen and Karjalainen, 2017). Social networks and social media stimulate companies and clients to produce products collaboratively and co-create value (liang et al., 2016a). Thus, social manufacturing involves the shared participation of companies and individuals in producing goods and products (Hamalainen and Karjalainen, 2017). Co-creation occurs in the social manufacturing environment, in various stages, including product design, engineering, production, marketing, and distribution (Mohajeri, 2016).

Social manufacturing is classified into two phases, the first, with an enterprise focus, called institutional social manufacturing, and the second focuses on the individual, known as diffuse social manufacturing (Hamalainen and Karjalainen, 2017). The second phase, also called the final phase, represents a revolution in multiple dimensions. Not only is it a technological revolution, but it is also a form of social and economic rupture in the manufacture of goods and services (Mohajeri, 2016).

According to Schneider (2018), businesses must adapt their business models for Industry 4.0 since customers pay for tangible assets and value-added services. Hence, it is not sufficient to only change the business' value proposition. A study from Shang et al. (2020) shows how Social Manufacturing can benefit several industries - i.e., fashion manufacturing, furniture, mobile phones, etc. - with a high demand for personalized items. Moreover, sustainability has become highly relevant for modern businesses. As Mohajeri et al./ (2020) studied, companies can resolve environmental issues, such as waste management, by joining forces through social manufacturing principles. Moreover, social manufacturing networks develop an ecological enterprise circle (Liu and Jiang, 2019), creating environmentally friendly processes.

The current COVID-19 pandemic has created a global state of calamity and emergency, drastically affecting the supply chain (Patel et al., 2020). The lack of health care material has created the need for new initiatives, mainly by using emerging technologies, to support this skyrocketing demand, evolving into a "citizen supply chain." For example, the creation of a "maker community," where anyone with a 3D printer at home can access free designs of face-shields/visors and contribute to producing these healthcare items. This initiative is the biggest collaborative project in modern history (Larrañeta et al., 2020).

With the emergence of this new manufacturing paradigm, this study addresses the following question: How advanced is the adoption of social manufacturing in recent contemporary manufacturing? The main objective is to confront the idea of social manufacturing from a theoretical and practical point of view, identifying academic and practicable opportunities to explore. The present scientific research article is organized as follows: firstly, the research method is presented; next, the state-of-the-art is analyzed, discussing the main aspects of social manufacturing and the characteristics that make it viable; following that, the next topic analyses the state of the practice, with some examples of companies/practical cases of social manufacturing; furthermore, the results of the research 
present comparative and analytic characteristics of the state of the art and practice; lastly, conclusions and recommendation for further studies is presented.

\section{RESEARCH METHOD}

The methodological procedure is structured into three main parts, as shown in Figure 1. Initially, articles related to the research theme were researched and selected. After that, a bibliographic review and content analysis of the articles was performed to describe and explain the paradigm of social manufacture. Hence, consolidating the concept of social manufacturing.

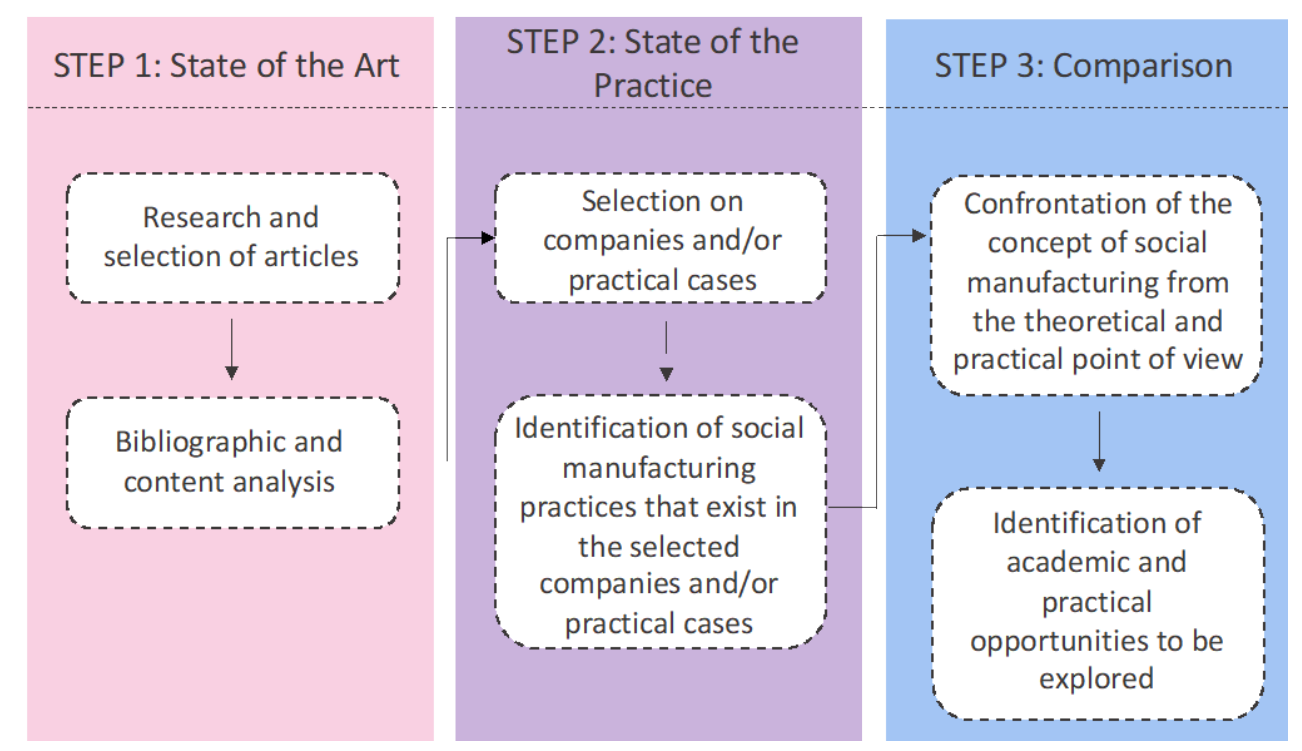

Figure 1. Methodological Procedure Source: The authors

The second step covers the study of the practice of this new production method. This part depends on bibliographic analysis, as it is necessary to have a well-defined concept of social manufacturing to evaluate the practical examples. The first step was selecting companies or applicable cases that make use of this new production paradigm. After that, it was necessary to identify all social manufacturing practices existent within the selected subjects.

Finally, the last step consists of the main objective of this study, separated into two sub-stages: the confrontation between theory and practice, as well as the identification of future academic and practical opportunities. This part depends heavily on steps 1 and 2 , and is therefore presented after them.

\section{Method for the literature analysis}

A systematic literature analysis identifies and selects research to answer a defined question (Mackenzie et al., 2012). Moreover, it is essential to understand the current development of scientific research and identify possible gaps (Brandenburg et al., 2014).

Articles were researched in two primary databases containing main scholarly journals on engineering, technology, and other scientific areas: Scopus (www.scopus.com) and Web of Science (www.webofknowledge.com), (Uhlmann and Frazzon, 2018). The following terms were searched, followed by the Boolean operator "or": "Soci* Manufac*," "City manufac*" and "Soci* supply chain*." Moreover, the search was filtered according to the parameters illustrated in Table 1. 
Table 1. Filters applied for the literature analysis

\begin{tabular}{ccc}
\hline \multirow{2}{*}{ Database } & \multicolumn{2}{c}{ Applied Filters } \\
\cline { 2 - 3 } Scopus & Parameter & Filter \\
\hline & Type of Document & $\begin{array}{c}\text { Article } \\
\text { Proceedings Papers } \\
\text { Revision }\end{array}$ \\
\cline { 2 - 3 } & Font of Article & $\begin{array}{c}\text { Journals } \\
\text { Leb of Science }\end{array}$ \\
\cline { 2 - 3 } & Lype of Document & Conference Procedures \\
\hline Language & English \\
\hline & & $\begin{array}{c}\text { Article } \\
\text { Proceedings Papers } \\
\text { English }\end{array}$ \\
\hline
\end{tabular}

Source: The authors

After the initial screening filtered according to eligibility, duplicates and articles unrelated to social manufacturing were removed. Figure 2 shows the structure used for the literature analysis following the PRISMA method - Preferred reporting items for systematic reviews and meta-analysis - (Moher et al., 2009).

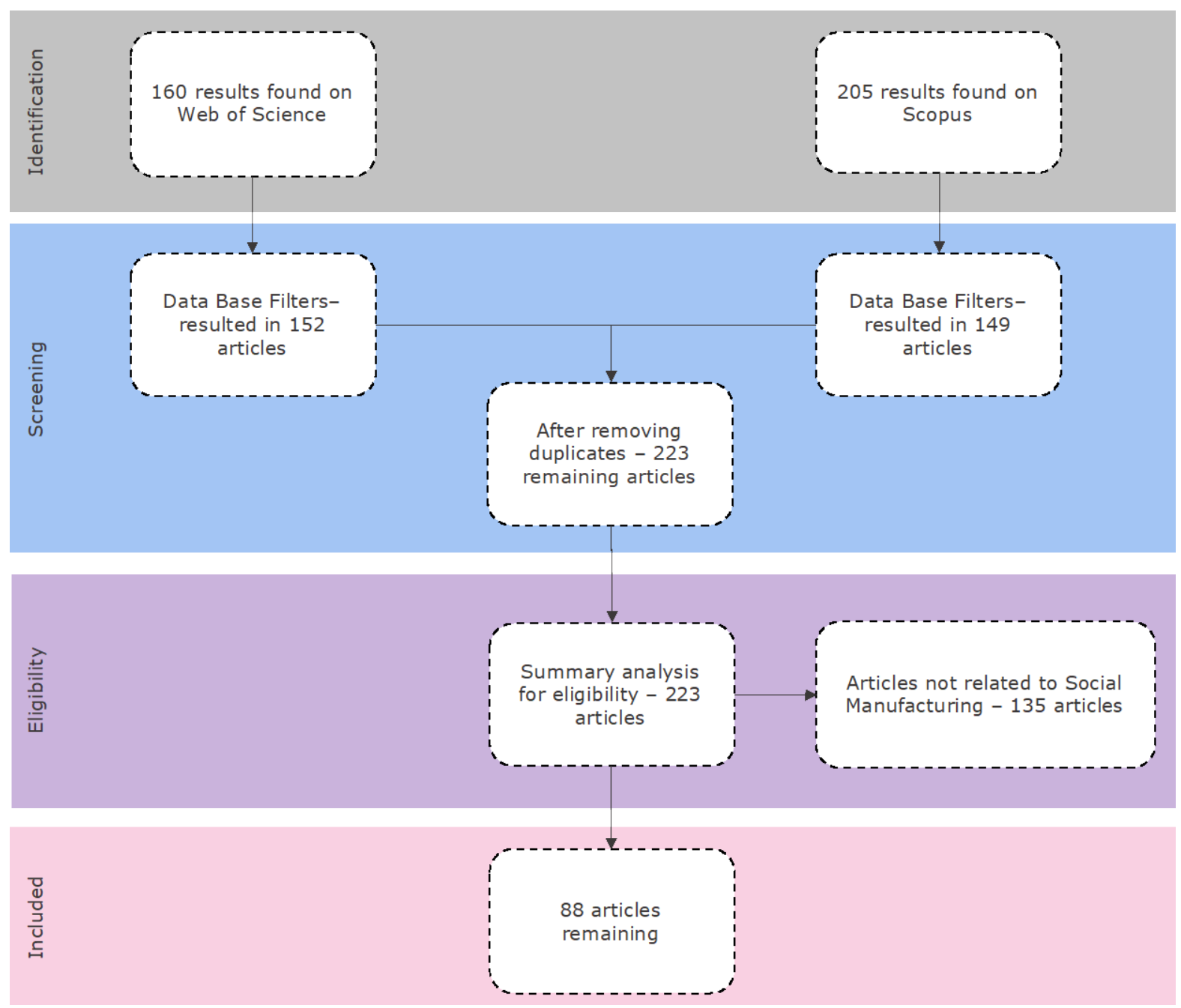

Figure 2. PRISMA method

Source: The authors 


\section{Plan for the practical analysis}

Figure 3 illustrates the methodology adopted for the study of the practice. It was developed based on Fink (2019) and Krippendorff's (Giannantonio, 2010) research methodologies but adapted for empirical research. Initially, it defined relevant research questions for studying the practice in the framework of social manufacturing. After that, determined research sources and models or practical applications were selected.

Then, the chosen companies were briefly described to understand their operation.

Furthermore, data was gathered from the models to answer the research questions. Finally, results were presented, followed by relevant discussions.

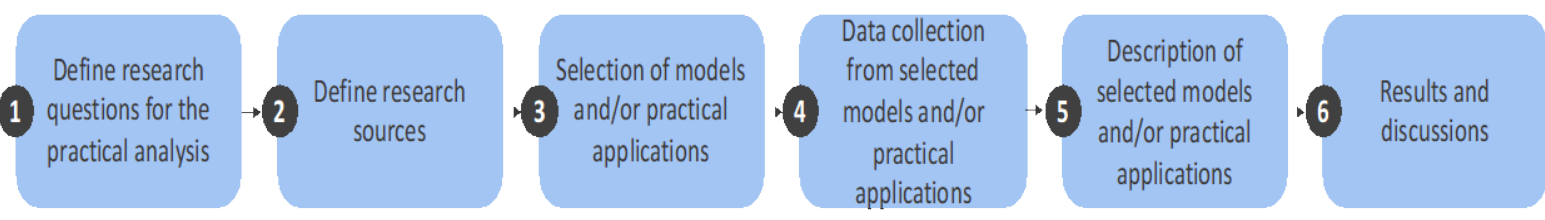

Figure 3. Methodology for the study of the practice Source: The authors

Research questions the empirical study seeks to answer:

1. What is the level of individual participation?

2. What is the classification of their value chain?

3. At which stage of social manufacturing is the company?

For selected models, research was performed on secondary materials available on the Internet and models or practical applications were analyzed as described in published academic articles.

Table 2 illustrates the search for the data source based on the interpretation of the surveyed contents, where extracted data and information are needed to answer the research questions of the practical study.

Table 2. The data source for the practical analysis

\begin{tabular}{cc}
\hline Data & Source \\
\hline Basic Information & Name \\
& Branch \\
& Location \\
\hline Question 1 & Individual participation in the value chain \\
\hline Question 2 & Terms under social manufacturing context \\
\hline Question 3 & Words and phases of social manufacturing \\
\hline
\end{tabular}

Source: The authors

\section{STATE OF THE ART}

Social manufacturing is based on mass socialized manufacturing services that are selforganized and oriented to services. It focuses on integrating resources proactively during a product's lifecycle (liang and Leng, 2017). This decentralized-resource integration occurs by employing cyber-physical-social interconnections through information networks and the internet of things (Xiao et al., 2019).

According to Jiang et al. (2016a), prosumers, cyber-physical-social systems, social interaction, prosumer relationship, community, and social context are essential elements of social manufacturing, explained as follows: 
- Prosumers: consumers have a double role as producers ( $p r o=$ producer and sumer $=$ consumer), (liang and Leng, 2017). Ideally, all individuals involved in social manufacturing should be prosumers (liang et al., 2016a);

- Social-cyber-physical systems (SCPS) consist of the union of the physical, cyber, and social spheres. The first consists of physical objects (hardware, signals, etc.) and empirical things (efficiency, information system, etc.). To create the cyber-physical system (CPS) it is necessary to join the physical and the cyber worlds. The last is formed by syntactic objects (structure, data, etc.) and semantic objects (meaning, validation, etc.). However, the CPS is insufficient to support social-technical manufacturing systems. For that, it is necessary to consider the social world that englobes pragmatic elements (intensions, communication, etc.) and elements of the social world (law, culture, etc.), (Yao and Lin, 2016). In summary, an SCPS enables social interaction and organic connections so that individual products and services can be co-created (Ding and Jiang, 2016);

- Social interaction is a cognitive process that varies throughout, enabling the interaction between prosumers, characterized by personal requisites or preferences. Thus, it is fundamental that these relationships are established and cultivated (Leng and Jiang, 2016; Jiang and Leng, 2017);

- Prosumer relationship: it is the reality of their interactive collaboration that results from the combination of demand and manufacturing capacity (Leng et al., 2014; Ding et al., 2016; Leng et al., 2017);

- The social manufacturing community is a dynamic unit of interrelated prosumers joined by a common goal of making an individualized product or service. Hence, to find a functional requisite or performance experience (Cao and Jiang, 2012; Ding et al., 2013; Ding et al., 2016). Prosumers are auto-organized as a different manufacturing community (Leng and Jiang, 2017), an autonomous, complex, and dynamic system (Xiao et al., 2019). Furthermore, the community should evolve to self-adapt prosumer's relations to reach a selforganized ecosystem (Cao and Jiang, 2012; Ding et al., 2013; Ding et al., 2016);

- Social Context: considers, concurrently, the mean, the result of the social interaction, and the historic operational event. Using analysis technics, it is a source of community and participant growth. Being a starting point of knowledge based on decision-making enhances the product's performance or effect (Ding and Jiang, 2016; Leng and Jiang, 2016; Jiang and Leng, 2017).

In a social manufacturing system, the community consists of many prosumers interested in shared activities. Different users can perform the outsource or the insource of action according to their necessities or capacities, or consequently, in an environment of virtual manufacturing to perform a given activity with the support of social computing (liang and Leng, 2017). According to outsourcing or crowdsourcing, prosumers are self-organized as a different manufacturing community, recognized as a complex and dynamic autonomous system (Xiao et al., 2019).

The term social manufacturing describes the phenomenon of shared participation between companies and individuum in the production of consumer goods. Notwithstanding, there is still no established definition of how this sharing occurs. Different authors have already described the term, adopting two main visions: firm-centric, or institutional, and individual-centric, or diffuse (Hamalainen and Karjalainen, 2017).

The institutional view is based on low individual participation and encompasses distributed manufacturing, mass customization, and personalization. On the other hand, the diffuse features a revolutionary and innovative production method led by prosumers, including peer-to-peer production, fabbing, and personal fabrication. This distinction suggests different levels of individual participation in the productive process as a whole (Hirscher et al., 2018).

Moreover, the social manufacturing era stimulates the coordinated creation of the shared community with the help of social manufacturing platforms and new non-hierarchical 
and emerging organizations. Furthermore, the crescent networked global economy forces enterprises and nations to think beyond traditional supply chain concepts (Xiong et al., 2018). For Rossit et al. (2019), it is necessary to develop robust scheduling approaches based on cyber-physical production systems (CPPS) to face different and unforeseen stresses on distributed production processes. Additionally, seeing their environment as a business ecosystem in rapid evolution, suppliers and consumers are embedded to co-create product value (Xiong et al., 2018).

Social manufacturing has some distinct characteristics (liang et al., 2016b):

- It creates and delivers value indirectly through a decentralized production;

- It consists of scattered-coupled communities that embrace a high number of prosumers with common interests, capacities, activities, and objectives;

- Social power structures drive internal and external manufacturing communities, becoming an ecosystem of self-interested individuum with similar opinions;

- Its final goal is to enable consumers to individualize their products and, finally, lead to mass individualization production.

Guo et al. (2021) define five critical fundamentals of social manufacturing:

- Communities with complex networks;

- Extended CPS framework for industrial nodes with three main layers - physical, cyber, and social;

- Collective intelligence - since the system is of multiple similar and different individuals;

- Blockchain for cyber credits - necessary to control the peer-to-peer community and help to choose reliable partners;

- Matched industrial software framework and models - integration of social media and enterprise software.

Social manufacturing can also support sustainable, healthy, and green development (Rusinko, 2007). It can satisfice individual consumer necessities and effectively fulfill their material needs. Hence, it can save materials and energy, diminishing environmental pollution (Xiong et al., 2018).

According to Mohajeri (2016), the current manufacturing stage is far from social manufacturing. Moreover, four main changes should accomplish the new manufacturing model. The modifications should happen in the following fields: manufacturing strategies, business models, value chain, and manufacturing technologies.

The transition will occur in two main phases, the "intermediate phase" and the "definitive stage." First, consumers will be more involved in the whole value chain, hence, maximizing cocreation. However, this represents only an improvement in the existing manufacturing paradigm. On the other hand, the second phase considers that all involved players will connect to a global platform where all can receive and send manufacturing requisites under demand. Furthermore, this connection can be held in any place and at any time. Therefore, social manufacturing in its most advanced stage is democratized fully through the people in society, thus, being wholly radical and disruptive compared to the current manufacturing paradigm (Mohajeri, 2016).

The prosumer capitalizes entirely in the last phase of social manufacturing. Each consumer can use social media to suggest a product idea in its design phase, develop a prototype, and become involved in its production process. Therefore, it can transform consumers into entrepreneurs by selling their ideas through their businesses. That is why the final picture is to create a paradigm in manufacturing in which society can become actively involved (Mohajeri, 2016).

There is a clear analogy with the IT industry, in which the intranet, a platform that enables information exchange intra-organizations, was replaced by cloud solutions. In this case, the manufacturing industry is evolving similarly but in a slow rhythm. The intermediate phase is 
similar to the intranet service, where the consumer assumes the role of co-creator. However, this stage is still limited by the existence of an enterprise. Notwithstanding, the advanced phase is a platform of under-demand manufacturing controlled by the public and where everyone can share and receive cyber, physical, or social requisites.

\section{CONSOLIDATION OF THE SOCIAL MANUFACTURING CONCEPT}

Industry 4.0 enabled the introduction of multiple manufacturing paradigms, one of them being social manufacturing, which academia has increasingly discussed. Thus, the following consolidates the concept: "social manufacturing is a collaborative production, with the active participation of prosumer communities throughout its value chain, being centered on the individual (individual-centric), enabling everyone to manufacture any product without geographical or time constraints."

In Figure 4 the house of social manufacturing (HSM) is proposed. The main idea behind this paradigm is to enable both on-demand production as well as mass individualization. Thus, it seeks more significant participation of the individuum in the selective process, a raise in sustainability, and an enhancement in providing a better response to contemporary customer demand, which increasingly demands personalized goods. Therefore, these terms form the roof of the HSM. Bicocchi et al. (2019) state that the agile supply chain's responsiveness is related to mass customization, which can adapt to changes in the demand, providing customers with personalized products.

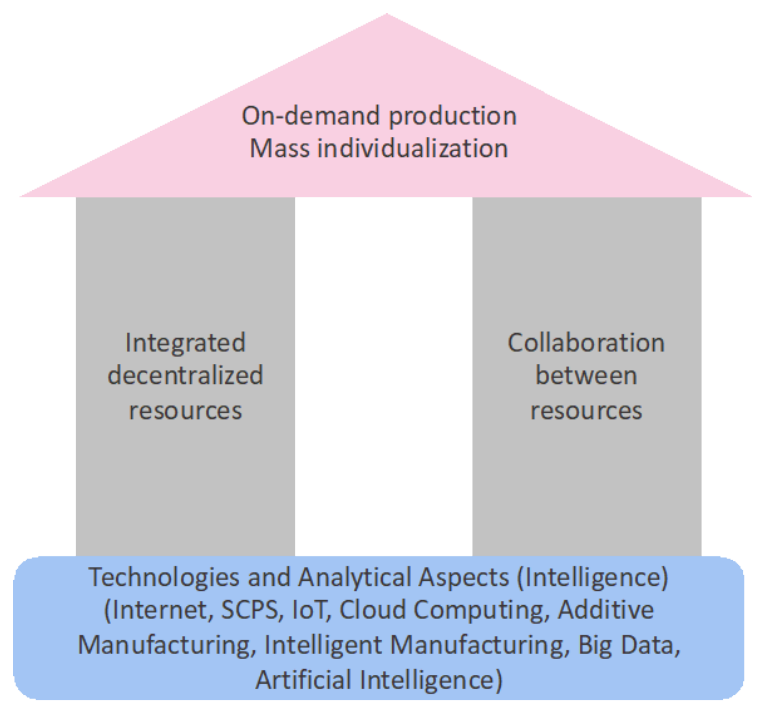

Figure 4. House of social manufacturing Source: The authors

For these objectives, two main pillars of HSM are defined. The first is the integrated decentralized resources, which form the dynamic communities of prosumers through connection via platforms, maintaining a common goal among all participants. The second is the collaboration between resources based on intra- and inter-community cooperation to reach the primary goal. The second is the collaboration between resources found on intraand inter-community partnerships to achieve the primary goal.

However, it must be founded on solid technologies for the house to sustain itself. Hence, the base of the HSM is composed of technologies such as the internet, social-cyber-physical systems, loT, cloud computing, additive manufacturing, and intelligent manufacturing. The technologies also include the analytical aspects that mainly involve machine intelligence and data.

In Figure 5 a social manufacturing adoption model is proposed based on the models by Mohajeri (2016); Hamalainen et al. (2018); Hamalainen and Karjalainen (2017). 


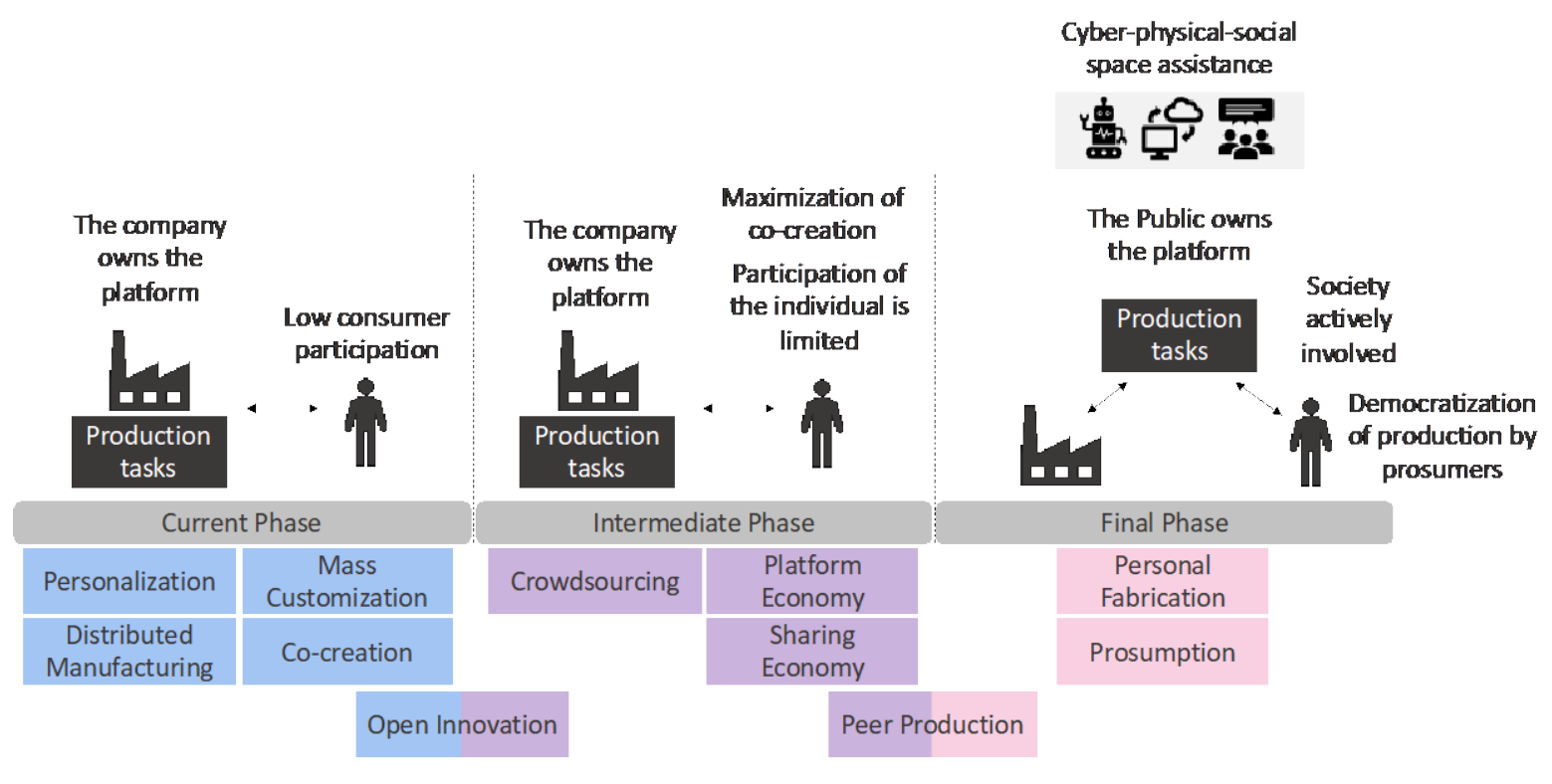

Institutional

Diffuse

Figure 5. Adoption model of social manufacturing

Source: The authors

The current phase represents the prevailing manufacturing model, classified as institutional or firm-centric. There is an attempt to insert the consumer into production processes, but this participation is quite limited. Additionally, current manufacturing systems already has technologies developed with industry 4.0, supported by cyber-physical systems. The terms related to this phase are personalization, mass customization, distributed manufacturing, and co-creation because they have little consumer participation in their production processes. Open innovation is a transitory concept that tends to the intermediate manufacturing phase because it considers individual involvement.

The consumer gains more visibility in co-creation in the intermediate phase, but their participation remains limited since they still control the production processes.

In this way, there is still an institutional model. The terms applied in the intermediate phase are crowdsourcing, platform economy, and sharing economy, as they have partial participation of the consumer in most of their value chain. Classified as peer production, the transitory term tends to the last phase of social manufacturing.

In the final phase, there is a total transformation in the business model. The company will no longer control the value chain as the public will become the platform's owner. Prosumers and society will democratize production become socially active.

To make this possible, cyber-physical-social systems will aid communication among the participants. The main terms at this stage are personal fabrication and prosumption, as they have high individual participation. In this way, diffuse or individual-centric manufacturing is created.

\section{STATE OF THE PRACTICE}

\section{Results of the practical research}

Initially, it described the operation of each company. Then, this information is analyzed separately in two sections: (1) fundamental analysis, where collected basic information about the selected companies, and (2) specific analysis to answer the research questions raised.

The research questions analyze only three processes in the value chain: creation, design, and manufacturing, as classified by Hamalainen et al. (2018). 
The first one deals with the idealization of the product, that is to say, raising its aspects and properties. The second deals with the product's physical definition, such as format, color, layout, size, among others. Finally, the third relates to the production process, which results in a finished product.

In addition, for a better understanding of the following schemes, the following participants in the process are defined:

- Client: an individual who wishes to acquire the final product;

- Individual: an individual who helps in the process without necessarily obtaining the final product;

- Company: legal entity.

The level of participation within the value chain processes into three intensities is classified by Hamalainen et al. (2018) as: main, partial, and minor. A "none" rating is considered if there is no individual participation.

\section{Selected companies}

The models were initially selected by searching for keywords in both English and Portuguese in the Google search tool (www.google.com). Terms such as: "customer coproduction", "collaboration between customer and company", "prosumer participation", "customer co-creation", among others, were searched. Additionally, companies already studied other academic articles (Hamalainen et al., 2018) or similar business models. Table 3 briefly describes the companies chosen for the practical study.

Table 3. Selected companies for the practical analysis

\begin{tabular}{|c|c|c|}
\hline Company Name & Description & Web Site \\
\hline Makexyz & On-demand 3D printing service. & makexyz.com \\
\hline MADE.COM & $\begin{array}{l}\text { Projects, produces and sells } \\
\text { furniture and objects for the } \\
\text { home. }\end{array}$ & made.com \\
\hline Fabbly & $\begin{array}{c}\text { Purchase and sale of files for 3D } \\
\text { printing. }\end{array}$ & fabbly.com \\
\hline Quirky & $\begin{array}{l}\text { Produces and markets products } \\
\text { invented by consumers. }\end{array}$ & quirky.com \\
\hline SeeedStudio & Manufacturing as a service. & seeedstudio.com \\
\hline Shapeways & On-demand 3D printing service. & shapeways.com \\
\hline Lego & $\begin{array}{l}\text { Projects, produces and markets } \\
\text { modular toys. }\end{array}$ & ideas.lego.com \\
\hline Bow \& Drape & $\begin{array}{l}\text { Design, produce and market } \\
\text { customizable clothing. }\end{array}$ & bowanddrape.com \\
\hline Ministry of Supply & $\begin{array}{l}\text { Design, produce and market } \\
\text { knitted clothing in a 3D printing } \\
\text { machine. }\end{array}$ & ministryofsupply.com \\
\hline $\begin{array}{l}\text { Al-Robotics vs. COVID-19 } \\
\text { initiative of the EU }\end{array}$ & $\begin{array}{l}\text { Centralizes and shares ideas and } \\
\text { projects related to Al and Robotics } \\
\text { to fight the COVID-19 }\end{array}$ & $\begin{array}{l}\text { ec.europa.eu/digital-single- } \\
\text { market/en/news/join-ai-robotics-vs- } \\
\text { covid-19-initiative-european-ai- } \\
\text { alliance }\end{array}$ \\
\hline Coronathon Community & $\begin{array}{l}\text { Outsourcing of face-shield } \\
\text { production }\end{array}$ & coronathon.com.ar \\
\hline
\end{tabular}

Source: The authors themselves 
Diagrams of the participation of agents in the business models for a better understanding of the selected companies were elaborated (Figure 6). It shows three types of arrows to represent the participation of agents in the business models: a straight arrow (central participation), a dashed arrow (partial participation), and a grey arrow (little participation).
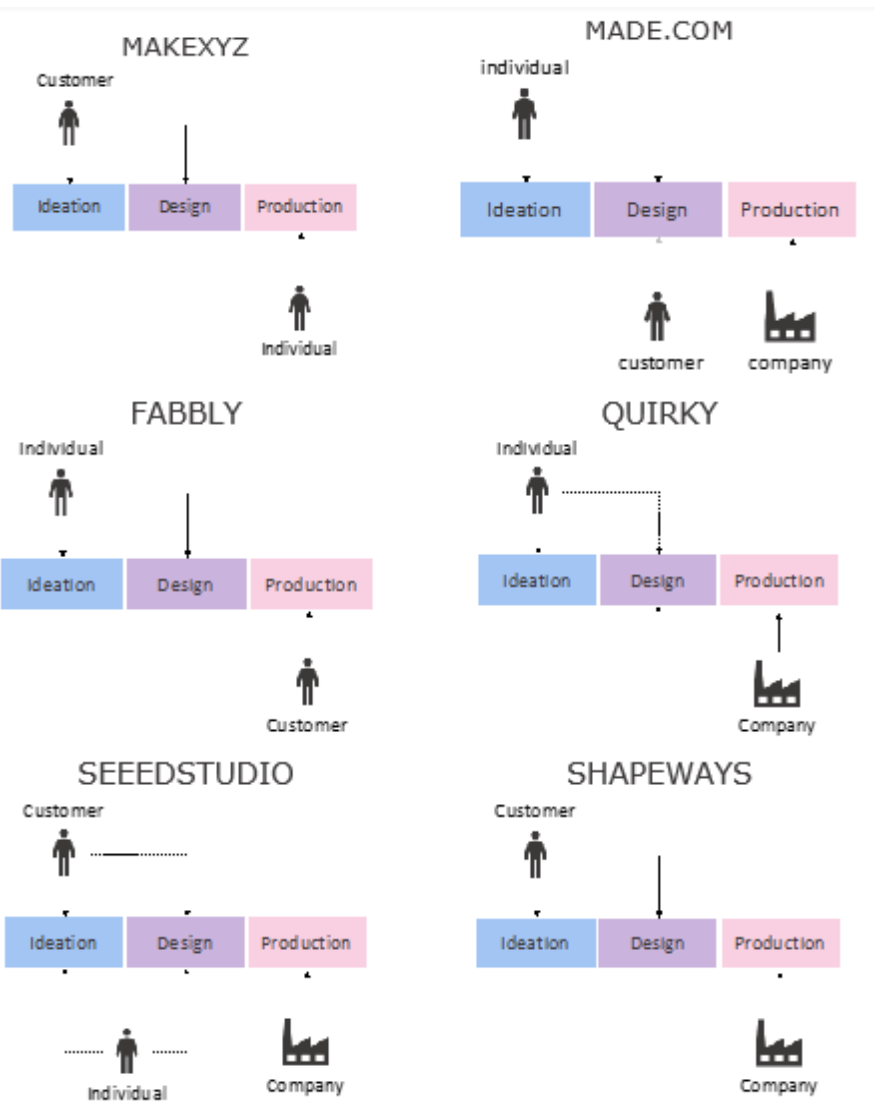

LEGO
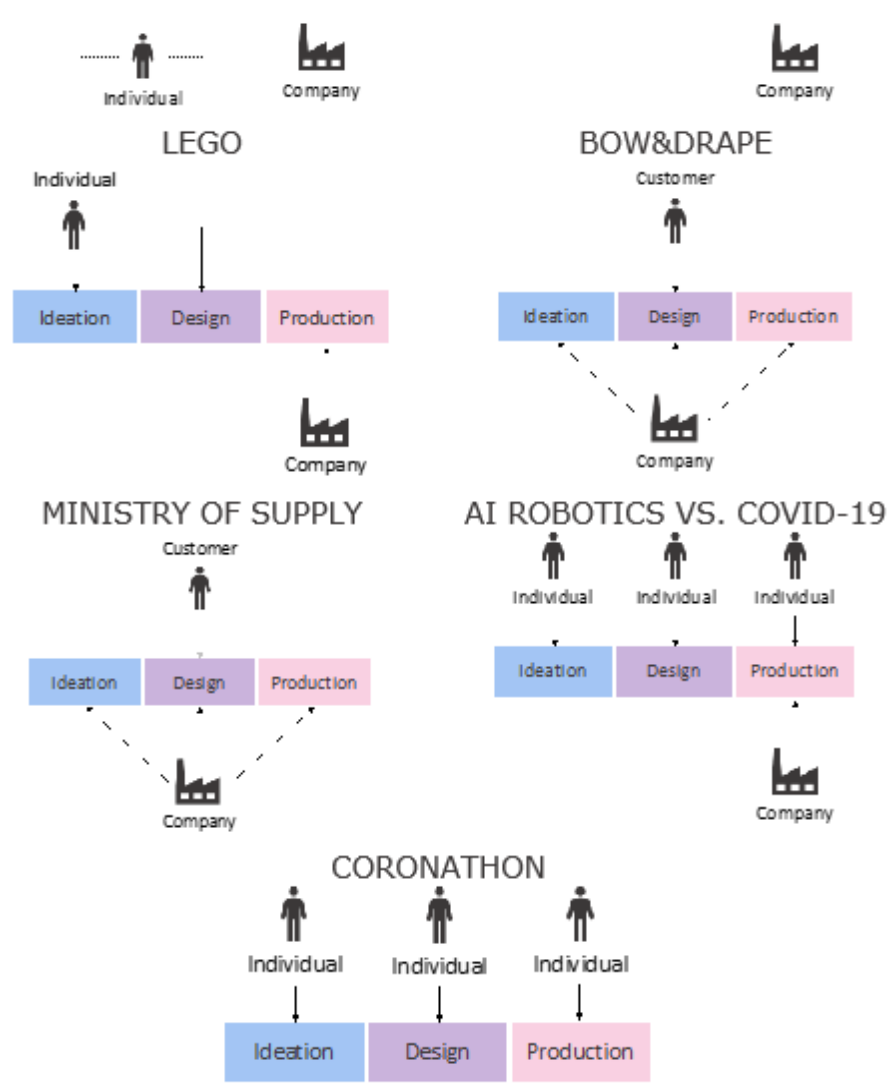

Figure 6. Participation of agents in the business models Source: The authors 
Table 4 shows the essential characteristics of the companies analyzed, including their industry and location in order to understand the portfolio of selected corporations.

The aim was to choose companies from different sectors and activities, thus making it possible to analyze the context of the industry as a whole and not only of a specific one. In addition, most businesses have a global presence. They are predominantly an online platform that provide products to the entire world.

Table 4. Basic information on the selected companies

\begin{tabular}{ccc}
\hline Name & Branch & Location \\
\hline Makexyz & 3D Printing & Global \\
\hline MADE.COM & Furniture and House decoration & Europe \\
\hline Fabbly & 3D Printing & Global \\
\hline Quirky & Multistore & USA \\
\hline SeeedStudio & Electronics & Global \\
\hline Shapeways & 3D Printing & Global \\
\hline Lego & Toys & Global \\
\hline Bow \& Drape & Fashion & USA \\
\hline Ministry of Supply & Fashion & USA \\
\hline Al Robotics vs. COVID-19 & Health & Europe \\
\hline Coronathon & Health (3D printing) & Argentina \\
\hline
\end{tabular}

Source: The authors

\section{Level of individual participation}

Table 5 summarizes the classifications according to the interpretation of the collected data.

Table 5. Individual participation in the value chain of the selected companies

\begin{tabular}{cccc}
\hline Company & Creation & Design & Production \\
\hline Makexyz & Main & Main & Main \\
\hline MADE.COM & Main & Main & Main \\
\hline Fabbly & Main & Main & None \\
\hline Quirky & Main & Partial & None \\
\hline SeeedStudio & Main & Partial & None \\
\hline Shapeways & Main & Main & None \\
\hline Lego & Main & Main & None \\
\hline Bow \& Drape & None & Partial & None \\
\hline Ministry of Supply & None & Minor & Main/None \\
\hline Al-Robotics vs. COVID-19 & Main & Main & Main \\
\hline Coronathon & Main & Main &
\end{tabular}

Source: The authors

It is pretty standard for companies to have a certain level of participation in creativity and design but low participation in manufacturing. The individual only has relevant participation in manufacturing at Makexyz and Fabbly, two companies in the 3D printing industry, and at Coronathon. This 3D printing community focuses on producing face shields to fight COVID-19. Furthermore, at AI-Robotics vs. COVID-19, the main idea is to centralize and share open-source projects and ideas in the field of robotics and Al. Production can be either made by groups of individuals or by companies.

In most cases, it is more common to see principal ownership in creativity, where the idea and requirements of products are defined, than in design. Only Bow \& Drape and the Ministry of Supply have shown low user participation in creativity, both in the fashion industry. 
Additionally, both have limitations on individual design participation, presenting only a few customization options.

MADE.COM, Shapeways, and Lego have significant involvement in creativity and design, but are low in manufacturing. The client is responsible for idealizing and designing his product, but the company performs the production. MADE.COM and Lego only manufacture the product if a defined number of people are engaged in the development.

Quirky and Seeedstudio have equal levels of participation throughout their value chain, as the client is responsible for defining the product and its characteristics. Still, in the case of Quirky, the final design is determined by the company, and at Seeedstudio, the pieces are modular and do not present many customization alternatives.

Coronathon has a primary level of individual participation throughout its value chain. Individuals are responsible for creating and designing face shields open-sourced to makers through a collaborative community. Makers will then use their 3D printing machines to fabricate the product. On the other hand, different projects and ideas related to COVID issues are centralized and shared in the initiative Al-Robotics. These projects are created and designed by individuals, creating a peer-to-peer community. Hence, production can be provided by individuals or companies.

It is also possible to identify that companies in the same field have similar levels of interaction with the individual, such as Makexyz and Fabbly (3D printing) and Bow \& Drape, and Ministry of Supply (fashion). In addition, individual participation has seen the highest level of contribution in the 3D printing market and the lowest in the fashion market.

\section{Classification of the value chain}

Table 6 shows the classification of the respective companies.

Table 6. Value chain classification of the analyzed companies

\begin{tabular}{cc}
\hline Name & Classification \\
\hline Makexyz & Sharing Economy/ Platform Economy \\
\hline MADE.COM & Open Innovation \\
\hline Fabbly & Platform Economy \\
\hline Quirky & Open Innovation \\
\hline SeeedStudio & Peer Production/ Platform Economy \\
\hline Shapeways & Platform Economy \\
\hline Lego & Open Innovation \\
\hline Bow \& Drape & Personalization \\
\hline Ministry of Supply & Mass Customization \\
\hline Al-Robotics vs. COVID-19 & Peer Production \\
Coronathon & Personal Fabrication \\
\hline
\end{tabular}

Source: The authors

Makexyz is classified as sharing economy and platform economy for two reasons. First, because the company has no 3D printers and the owners are individuals. Secondly, because the company is a platform that connects customers (demand) with individuals (supply). A parallel can be drawn between its business model and that of Airbnb.

On the other hand, MADE.COM, Quirky, and Lego are classified as open innovation. The three companies present a similar value model proposal, where the individual has the idea and creates the product, and the company produces. Open innovation is currently used to replace or complement the R\&D of companies, performing crowdsourcing and user innovation. 
Bow \& Drape and the Ministry of Supply, even though they are from the same industry and present similar business models, have differences in their classification. Consider the former as customization. It is a more advanced version of mass customization, where the individual selects the product, buys it, and customizes it in a less restricted way.

Ministry of Supply, however, is a typical example of mass customization, where the user can choose certain pre-defined features for their final product, not having many different options.

Fabbly and Shapeways have been classified as platform economy. Both offer a platform where services are linked. The former provides 3D print files for other users to purchase. As such, it is like a file marketplace. The second prints the print files forwarded to the platform through its machines or third-party vendors.

The classification of Seedstudio's core activities are separate. The issue of selling modular parts and then producing prototypes can be classified as platform economy. Through the platform, it communicates with the customer. There is no physical store. On the other hand, when considering information sharing among peers through forums to help develop the prototype, the company also fits into the peer production category, where peers collaborate for standard production.

Coronathon can be classified as personal fabrication. It consists of a collaborative community of peers that are joined by the same objective. The community offers open-source projects of face shields and the material for their manufacture is bought with monetary donations. Makers, participants in the community, produce the face shields with their 3D printers following safety procedures. These are then donated to hospitals and medical centers that have subscribed to the program.

Al-Robotics vs. COVID-19 is classified as peer production. Contrary to Coronathon, the idea of this initiative is to share and let individuals collaborate in multiple projects that have been taking place throughout the European Union. However, its focus is not on the product itself but the phases of creation and design. Production can be either idealized by a group of individuals or a company itself.

The classification was made by analyzing the level of individual participation in the value chain and its business model, fitting it into the concepts already described. In this way, the analysis was only qualitative but sought to choose the classification that best matched its context. There may be more alternatives that were not taken into consideration.

A very relevant point to be commented on is that the classification of the terms regarding the intensity of individual participation in the value chain processes is not necessarily equivalent to the companies' category as per Question 2. This occurs because the previous analysis considered a micro scenario, analyzing each company by itself and was not classified by employing a comparison.

For example, in Lego, the individual's participation in the conception and design is paramount since the user has no influence, or help, from the company in these activities.

However, considering a more macro scenario, in a way, the company is limited by its business model; in the end, the product will be a toy manufactured with modular blocks.

\section{Social manufacturing phase}

To answer this question, the classifications made in Table 6 are necessary. In addition, the social manufacturing model, formulated in Figure 5, is taken into consideration. In this way, it was possible to classify the phase of the companies, as shown in Figure 7. 


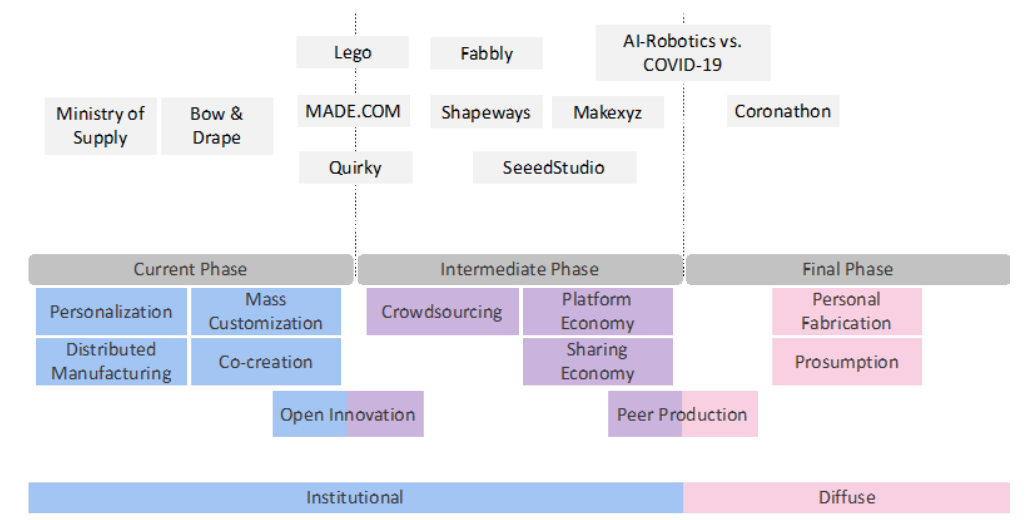

Figure 7. Social manufacturing phase of analyzed companies Source: The authors

Accordingly, two companies were classified in the current manufacturing phase: Ministry of Supply and Bow \& Drape. Lego, MADE.COM, and Quirky are in a transitory moment because they have open innovation in certain stages of their processes. In addition, all the others are classified in the intermediate phase since they use platform economy and sharing economy. Seeedstudio, although having a part ranked as peer production, has its core activities in platform economy due to a collaborative peer community, as such it is still in the intermediate phase. The initiative AI-Robotics vs. COVID-19 transitions between the middle and the final stage since it focuses on peer production. Nevertheless, Coronathon can be classified at the beginning of the final phase of social manufacturing due to its strong bond with the community to work for an organically grown common cause.

\section{COMPARING THE STATE OF THE ART AND THE STATE OF THE PRACTICE}

Social Manufacturing in practice and theory are compared in Figure 8 using the criteria defined in the House of Social Manufacturing (Figure 4).
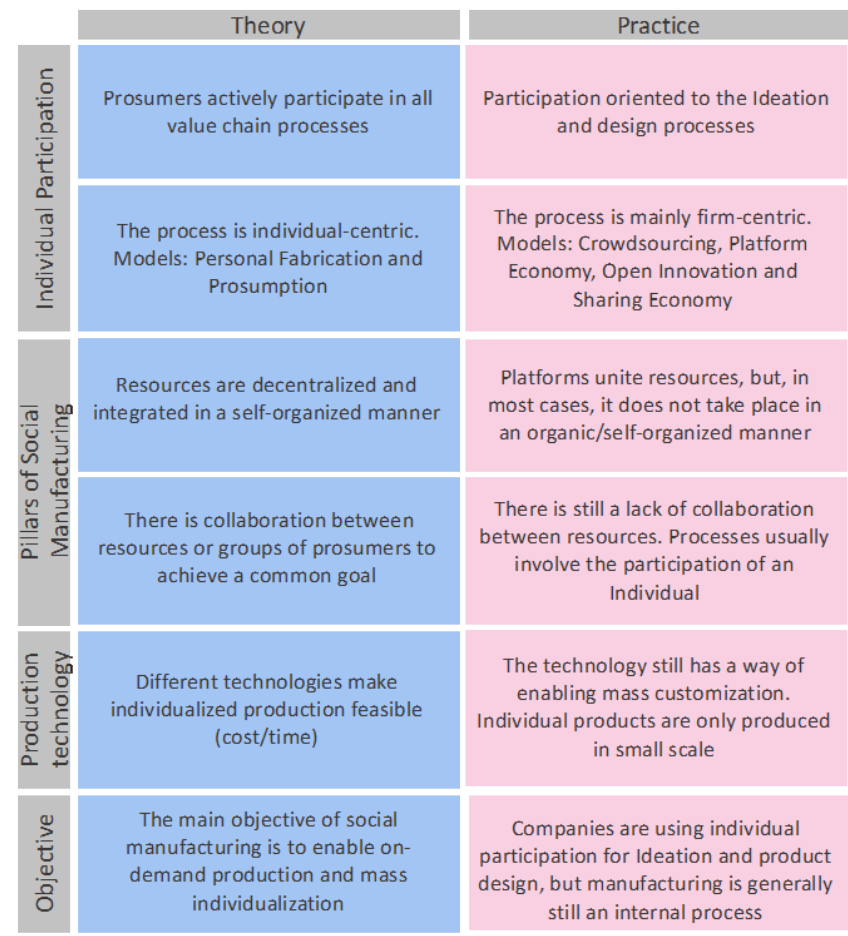

Figure 8. State of the theory and practice of social manufacturing Source: The authors 
To deeply understand the difference in social manufacturing between state of the art and state of the practice, a classification was developed based on relevant aspects raised in the bibliographical analysis. The categories are individual participation, pillars of social manufacturing (decentralized integrated resources and collaboration between resources), production technology (such as technologies that enable mass production, batches, etc.), and objective. Four levels were defined: current (0), initial (1), intermediate (2), and final (3). Figure 9 shows the categories.

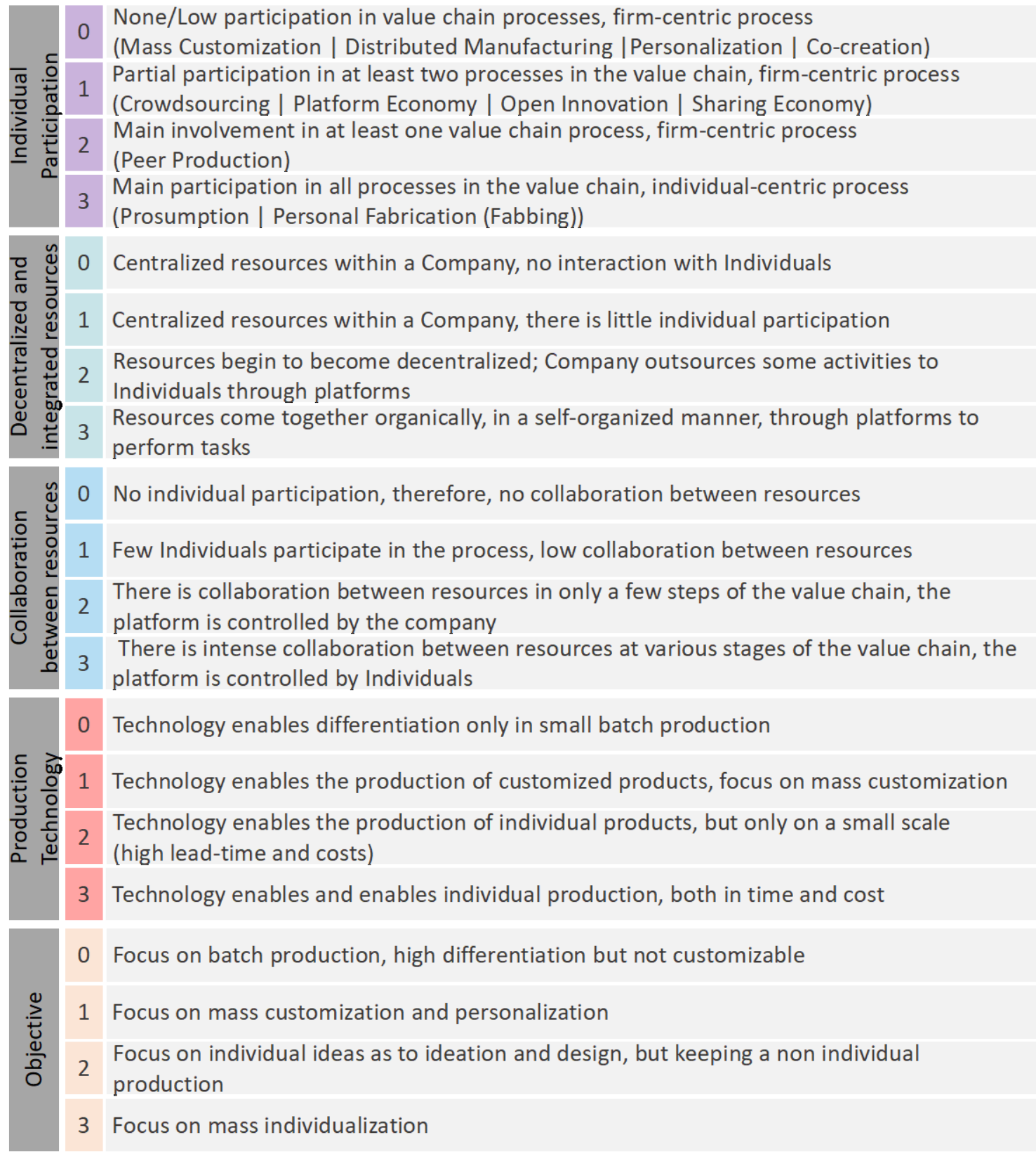

Figure 9. Classification to evaluate the level of social manufacturing Source: The authors

Furthermore, the sample analyzed in the practical study enabled a systematic classification shown in the radar graphs of Figure 10. In it, companies are categorized according to the characteristics raised in the experimental research study. The graphs take into account the scopes of analysis and classification levels. The outside of the radar represents level 3 - final, and the center level 0 - current. 

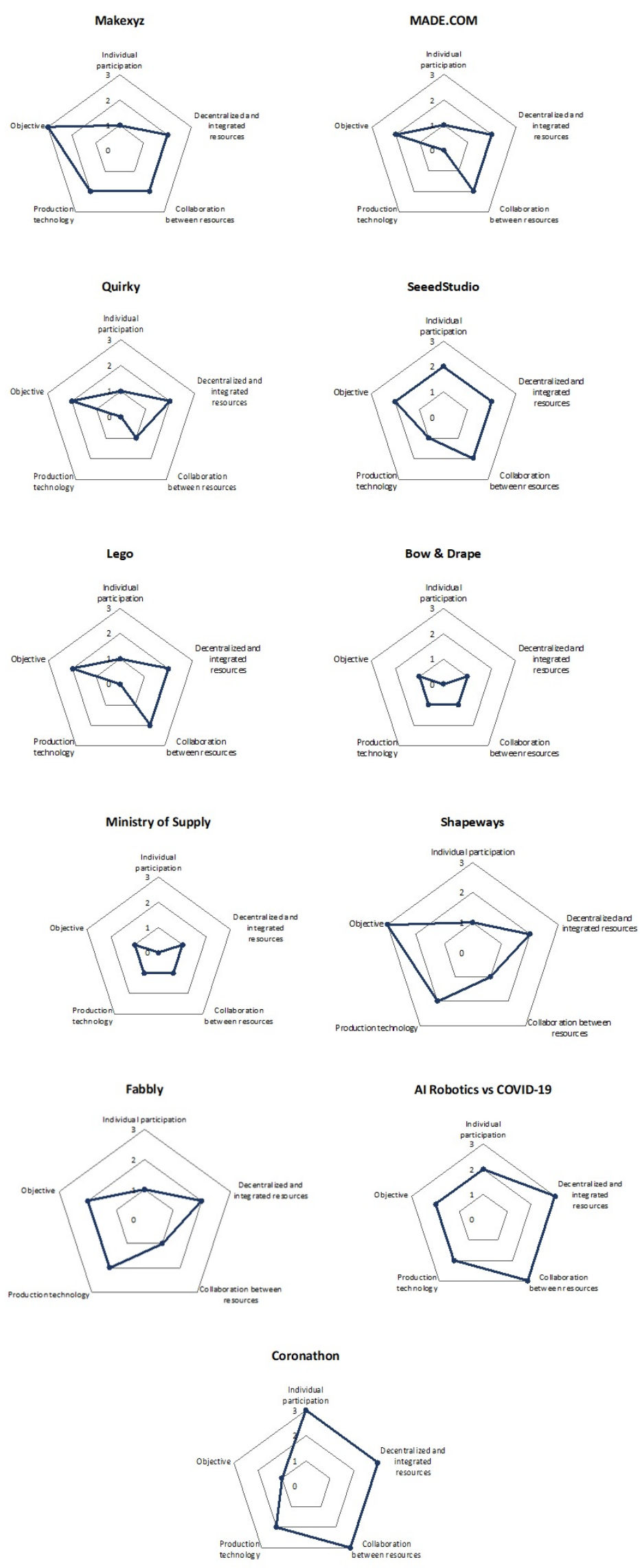

Figure 10. Classification of the analyzed companies Source: The authors 
For the criterion individual participation, most companies are at level 1, except for Seeedstudio, Ministry of Supply, Bow \& Drape, Al-Robotics, and Coronathon, which display, respectively, levels $2,0,0,2$, and 3 .

Most of the cases studied show partial individual participation in at least two processes in the value chain, although with the processes still classified as firm-centric. Seeedstudio, on the other hand, even being totally in the intermediate stage of social manufacturing, as presented in the forum of co-creation of peers, was classified in the second level. Al-Robotics was ranked at the same level as SeeedStudio since it is based on peer production. The Ministry of Supply and Bow \& Drape, both companies in the fashion industry, were classified as level 0 because they have low or no individual participation in their processes, being almost entirely firm-centric. Coronathon, different than the other examples, has individual-centric procedures, being classified in the third level due to its foundation in personal fabrication.

As for decentralized and integrated resources, most cases are classified at level 2, with only four exceptions, two companies in the fashion industry, which are still at level 1, and two in the health industry, already at level 3.

In most of the examples described in this study, the resources become decentralized, and companies begin to outsource activities to individuals through platforms. This is the case with 3D printing companies for instance, which outsource all product-related activities and focus only on controlling the platform provided.

Level 1 companies centralize the resources within a company and there is little individual participation, such as in the case of the examples analyzed, where it only occurs in product design. On the other hand, level 3 has decentralized resources gathered organically through an online platform that individuals control.

Collaboration of resources varies among the cases analyzed, obtaining three values. AlRobotics and Caoronathon show a level 3 due to a high collaboration of resources in most of their product's value chain processes. For Makexyz, MADE.COM, SeeedStudio, and Lego, the collaboration is classified as level 2 . These companies control a collaboration between resources of low magnitude in only a few steps of the value chain and the platform.

For the other cases analyzed, this variable assumes level 1 because very few individuals participate in the process and collaboration is relatively low. For example, in fashion companies, only one individual collaborates to manufacture their clothes.

In production technologies, firms have taken on levels 0,1 , and 2. At level zero are MADE.COM, Quirky, and Lego. Even if the creation and design are performed through crowdsourcing, allowing co-creation with the consumer, production is still performed in small batches of non-customizable units. On the first level are SeeedStudio, Bow \& Drape, Ministry of Supply, and Coronathon, as they focus on mass customization. The second level is Makexyz, Shapeways, Fabbly (companies that concentrate on selling files and producing 3D objects), and Al-Robotics.

The technologies that these companies employ enable the production of individual products, which is only viable on a small scale.

Lastly, the goal of companies is classified in levels 1, 2, and 3. In the first level is Bow \& Drape and the Ministry of Supply, whose primary focus is mass customization and customization of pre-defined products. Moreover, Coronathon is also classified in the first level even though it deals with organic, decentralized, and individual production. Its main objective is to produce functional face-shields for hospitals and not focus on personalization of products. The second level is MADE.COM, Quirky, SeeedStudio, Lego, and Fabbly, whose main objective is to maximize co-creation with individuals in creation and design while maintaining a non-individual production.

In addition, Al-Robotics can also fit in this classification since it focuses on individual creation and design but not on the product itself, whether personalized or not.

Makexyz and Shapeways are the only companies whose goal is mass individualization.

Therefore, it can be concluded that Coronathon and Al-Robotics are the companies that are closest to social manufacturing due to the constant cooperation between individuals in all 
processes in the product's value chain. Notwithstanding, their main objective is not mass individualization. Following behind, Makexyz and SeeedStudio are the companies that are the second closest to social manufacturing, although they do not yet idealize it since they are classified as level 2 in almost all analyzed aspects. Shapeways and Fabbly have very similar ratings, varying only in relation to the final objective of the company. It can be said that they are in a previous state of Makexyz and SeeedStudio. MADE.COM, Quirky, and Lego have similar final ratings, varying in level only with regard to resource collaboration. Their current state shows that they are at an overall manufacturing level inferior to that of the previously mentioned companies. Bow \& Drape and the Ministry of Supply have characteristics that rank them closer to the current manufacturing level.

\section{CONCLUSION AND RECOMMENDATION FOR FUTURE WORK}

Social manufacturing is in the early stages of development, mainly due to the significant definitions and the lack of practical examples. After consolidating and correlating the theory and experimental analysis, this research defined the current level of social manufacturing.

From the analyzed examples, it is possible to notice that only four cases are attributed certain variables that reach the hypothetical state of social manufacturing. Two of them have their objective set on social manufacturing, while other variables are still at an intermediate stage. The other two show high levels of collaboration, integration of resources, and individual participation. Therefore, it can be said that no practical example has fully reached the theoretical framework of social manufacturing. Notwithstanding, it is possible to say that the COVID-19 crisis has been encouraging and enabling the creation of prosumer communities, which is essential for the development of social manufacturing.

Based on the limitations of this study, some recommendations were identified for future work: (1) consider articles, case studies and models in languages other than English, such as Chinese, as well as also other databases relevant to this research; (2) interviews could help to improve the definition of business models and value propositions; and (3) develop a more complex model for assessing social manufacturing, taking more assessment levels and further comparative elements into account.

\section{REFERENCES}

Bicocchi, N., Cabri, G., Mandreoli, F. et al. (2019), "Dynamic digital factories for agile supply chains: An architectural approach", Journal of Industrial Information Integration. Vol. 15, pp. 111-21.

Brandenburg, M., Govindan, K., Sarkis, J. et al. (2014), "'Quantitative models for sustainable supply chain management: developments and directions", European Journal of Operational Research, Vol. 233, No. 2, pp. 299-312. http://dx.doi.org/10.1016/j.ejor.2013.09.032.

Cao, W. and Jiang, P. (2012), "Cloud machining community for social manufacturing", in Jiang Z.I., Li Y.G., Zhang X.P. et al. (Eds.), Advances in Manufacturing Technology. Trans Tech Publications Ltd, Zurich, pp. 61-64.

Ding, K. and Jiang, P. (2016), "'Incorporating Social Sensors and CPS nodes for personalized production under social manufacturing environment", Procedia CIRP, Vol. 56, pp. 366-71. http://dx.doi.org/10.1016/j.procir.2016.10.057.

Ding, K., Jiang, P. and Zhang, X. (2013), "A framework for implementing social manufacturing system based on customized community space configuration and organization", in Advances in Manufacturing Science and Engineering. Trans Tech Publications, Zurich, pp. 3191-4.

Ding, K., Jiang, P., Leng, J. et al. (2016), "Modeling and analyzing of an enterprise relationship network in the context of social manufacturing", in Proceedings of the Institution of Mechanical Engineers, Part B: Journal of Engineering Manufacture in London, England, 2016, Sage Publications, London, pp. 752-69.

Fink, A. (2019), Conducting Research Literature Reviews: From The Internet To Paper. Sage, Thousand Oaks.

Giannantonio, C.M. (2010), "Content analysis: an introduction to its methodology", Organizational Research Methods, Vol. 13, No. 2, pp. 392-4.

Guo, W., Li, P., Yang, M. et al. (2021), "Social manufacturing: what are its key fundamentals?", IFAC PapersOnLine, Vol. 53, No. 5, pp. 65-70. 
Hamalainen, M. and Karjalainen, J. (2017), "'Social manufacturing: When the maker movement meets interfirm production networks", Indiana University, Vol. 60, No. 6, pp. 795-805. http://dx.doi.org/10.1016/j.bushor.2017.07.007.

Hamalainen, M., Mohajeri, B. and Nyberg, T. (2018), "Removing barriers to sustainability research on personal fabrication and social manufacturing", Journal of Cleaner Production, Vol. 180, pp. 666-81. http://dx.doi.org/10.1016/j.jclepro.2018.01.099.

Hirscher, A., Niinimaki, K. and Armstrong, C.M.J. (2018), "'Social manufacturing in the fashion sector: New value creation through alternative design strategies?", Journal of Cleaner Production, Vol. 172, pp. 4544-54. http://dx.doi.org/10.1016/j.jclepro.2017.11.020.

Jiang, P. and Leng, J. (2017), "The configuration of social manufacturing: a social intelligence way toward service-oriented manufacturing", International Journal of Manufacturing Research, Vol. 12, No. 1, pp. 4. http://dx.doi.org/10.1504/IJMR.2017.083647.

Jiang, P., Ding, K. and Leng, J. (2016a), "'Towards a cyber-physical-social-connected and service-oriented manufacturing paradigm: Social Manufacturing", Manufacturing Letters, Vol. 7, pp. 15-21. http://dx.doi.org/10.1016/j.mfglet.2015.12.002.

Jiang, P., Leng, J. and Ding, K. (2016b), "Social manufacturing: a survey of the state-of-the-art and future challenges", in IEEE International Conference on Service Operations and Logistics, and Informatics, IEEE, Beijing, pp. 12-7.

Larrañeta, E., Dominguez-Robles, J. and Lamprou, D. A. (2020), "Additive manufacturing can assist in the fight against COVID-19 and other pandemics and impact on the global supply chain", 3D Printing and Additive Manufacturing, Vol. 7, No. 3, pp. 100-3.

Leng, J. and Jiang, P. (2016), "'A deep learning approach for relationship extraction from interaction context in social manufacturing paradigm", Knowledge-Based Systems, Vol. 100, pp. 188-99. http://dx.doi.org/10.1016/j.knosys.2016.03.008.

Leng, J. and Jiang, P. (2017), "Mining and matching relationships from interaction contexts in a social manufacturing paradigm", IEEE Transactions on Systems, Man, and Cybernetics. Systems, Vol. 47, No. 2, pp. 276-88. http://dx.doi.org/10.1109/TSMC.2016.2623630.

Leng, J., Jiang, P. and Ding, K. (2014), "Implementing a three-phase integrated decision support model for parts machining outsourcing", International Journal of Production Research, Vol. 52, No. 12, pp. 361436. http://dx.doi.org/10.1080/00207543.2013.879344.

Leng, J., Jiang, P. and Zheng, M. (2017), "Outsourcer-supplier coordination for parts machining outsourcing under social manufacturing", Journal of Engineering Manufacture, Vol. 231, No. 6, pp. 1078-90.

Liu, C. and Jiang, P. (2019), "Social factory as a production node of social manufacturing", Journal of Mechanical Engineering Science, Vol. 233, No. 14, pp. 5144-60.

Lu, Y. (2017), "Industry 4.0: A survey on technologies, applications and open research issues", Journal of Industrial Information Integration, Vol. 6, pp. 1-10. http://dx.doi.org/10.1016/j.jii.2017.04.005.

Mackenzie, H., Dewey, A., Drahota, A. et al. (2012), "Systematic reviews: what they are, why they are important, and how to eet involved", Journal of Clinical and Preventive Cardiology, Vol. 1, No. 4, pp. 193-202.

Mohajeri, B. (2016), Paradigm Shift from Current Manufacturing to Social Manufacturing. Masters Dissertation in Communications Ecosystems, Aalto University School of Science, Espoo.

Moher, D., Liberati, A., Tetzlaff, J. et al. (2009), "Preferred reporting items for systematic reviews and metaanalyses: the PRISMA Statement", International Journal of Surgery, Vol, 8, No, 5, pp. 264-9.

Patel, R., Babady, E., Theel, E.S. et al. (2020), "Report from the American Society for Microbiology COVID19 International Summit, 23 March 2020: Value of Diagnostic Testing for SARS-CoV-2/COVID-19", mBio, Vol. 11, No. 2, pp. e00722-20. http://dx.doi.org/10.1128/mBio.00722-20.

Rayna, T. and Striukova, L. (2016), "'Involving consumers: the role of digital technologies in promoting "prosumption" and user innovation", Journal of the Knowledge Economy, Vol. 12, pp. 218-37. http://dx.doi.org/10.1007/s13132-016-0390-8.

Rossit, D.A., Tohmé, F. and Frutos, M. (2019), "A data-driven scheduling approach to smart manufacturing", Journal of Industrial Information Integration. Vol. 15, pp. 69-79.

Rusinko, C. (2007), "Green manufacturing: an evaluation of environmentally sustainable manufacturing practices and their impact on competitive outcomes", IEEE Transactions on Engineering Management, Vol. 54, No. 3, pp. 445-54. http://dx.doi.org/10.1109/TEM.2007.900806. 
Schneider, P. (2018), "Managerial challenges of Industry 4.0: an empirically backed research agenda for a nascent field", Review of Managerial Science. Vol. 12, pp. 802-48.

Shang, X., Chen, X., Liu, L. et al. (2020), "Blockchain-based social manufacturing for customization production", IFAC PapersOnLine. Vol. 53, No. 5, pp. 53-8.

UhImann, I.R. and Frazzon, E.M. (2018), "Production rescheduling review: opportunities for industrial integration and practical applications", Journal of Manufacturing Systems, Vol. 49, pp. 186-93. http://dx.doi.org/10.1016/j.jmsy.2018.10.004.

Xiao, X., Wang, W., Zhang, L. et al. (2019), "Evaluating of dynamic service matching strategy for social manufacturing in cloud environment", Future Generation Computer Systems, Vol. 91, pp. 311-26.

Xiong, G., Wang, F.Y., Nyberg, T.R. et al. (2018), "From mind to products: towards social manufacturing and service", Journal of Automatica Sinica, Vol. 5, No. 1, pp. 47-57.

Xue, X., Wang, S., Zhang, L.J. et al. (2019), "'Evaluating of dynamic service matching strategy for social manufacturing in cloud environment", Future Generation Computer Systems, Vol. 91, pp. 311-26. http://dx.doi.org/10.1016/j.future.2018.08.028.

Yao, X. and Lin, Y. (2016), "'Emerging manufacturing paradigm shifts for the incoming industrial revolution", International Journal of Advanced Manufacturing Technology, Vol. 85, No. 5-8, pp. 1665-76. http://dx.doi.org/10.1007/s00170-015-8076-0.

Author contributions: R.M.Z. - main author, data collection, writing; E.M.F. - main supervisor and writing revision; I.R.U. - joint supervisor and writing revision. 